\title{
Imatinib Responsiveness in Canine Mast Cell Tumors Carrying Novel Mutations of c-KIT Exon 11
}

\author{
Yuko NAKANO ${ }^{1,2)}$, Tetsuya KOBAYASHI ${ }^{1)}$, Fukiko OSHIMA ${ }^{1)}$, Eri FUKAZAWA ${ }^{1)}$, Tetsushi YAMAGAMI ${ }^{3)}$, \\ Yozo SHIRAISHI ${ }^{3)}$ and Masamine TAKANOSU 3 (4)* \\ 1) Japan Small Animal Cancer Center, 2-27-4 Nakatomi-minami, Tokorozawa, Saitama 359-0003, Japan \\ 2) Division of Clinical Epidemiology, Research Center for Medical Science, Jikei University School of Medicine, 3-25-8 Nishi-Shinbashi, \\ Minato-Ku, Tokyo 105-8461, Japan \\ 3) Japan Small Animal Medical Center, 2-27-4 Nakatomi-minami, Tokorozawa, Saitama 359-0003, Japan \\ 4)Nasunogahara Animal Clinic, 2-3574-98 Asaka, Ohtawara, Tochigi 324-0043, Japan
}

(Received 20 March 2013/Accepted 15 November 2013/Published online in J-STAGE 29 November 2013)

ABSTRACT. In 2 individual cases of canine mast cell tumors, we identified 2 novel c-KIT mutations in exon 11: a 9-base pair (bp) deletion (c.1663-1671del) and a point mutation (c.1676T >A). The 9-bp deletion mutation caused a loss of 3 amino acids, corresponding to p.Gln555_Lys557del, and the point mutation resulted in the substitution of valine by aspartic acid (p.Val559Asp) in the juxtamembrane domain of the protein. Imatinib mesylate, a therapeutic agent for canine mast cell tumors, was used to treat both tumors. Complete remission was achieved at 33 and 14 days after administration, respectively. However, in both cases, the therapeutic response subsequently tapered with the duration of remission lasting 66 and 255 days, respectively. Although these 2 novel $c$-KIT mutations in exon 11 were not confirmed to be gain-of-function mutations, a further study may help clarify relevance between mutations identified in this report and responsiveness. KEY WORDS: canine, $c-K I T$, imatinib mesylate, mast cell tumor, mutation.

doi: 10.1292/jvms.13-0156; J. Vet. Med. Sci. 76(4): 545-548, 2014

The $c$-KIT gene encodes a transmembrane type III receptor tyrosine kinase. Gain-of-function mutations in this gene have been identified in canine mast cell tumors $[6,8]$. Although most exon 11 mutations identified thus far are internal tandem duplications (ITDs), other types, such as point mutations, deletions and insertions, have also been reported [8]. In vitro, a part of the mutations result in independent ligand-mediated constitutive phosphorylation of KIT and downstream signal transduction, which may result in the development and/or proliferation of certain canine mast cell tumors. Imatinib mesylate is a small-molecule tyrosine kinase inhibitor, which binds to an adenosine triphosphate-binding site on BCR-ABL, KIT, PDGF-R and ABL protein-tyrosine kinase, thus preventing downstream signaling. In humans, this drug has been successfully used as a therapeutic agent for Philadelphia-positive chronic myeloid leukemia and gastrointestinal stromal tumor carrying a $c-K I T$ mutation [1, 2]. In veterinary medicine, clinical studies have reported that imatinib mesylate is effective against canine mast cell tumors carrying the ITD mutation on $c-K I T$ in exon 8 or 11 and the c. $1523 \mathrm{~A}>\mathrm{T}$ mutation in exon $9[3,5,11]$. However, little is known regarding the clinical response of tumors with other exon 11 mutations to imatinib mesylate. In particular, deletions and point mutations comprise $20 \%$ of canine mast cell

*Correspondence to: Takanosu, M., Nasunogahara Animal Clinic, 2-3574-98 Asaka, Ohtawara, Tochigi 324-0043, Japan.

e-mail: volkerhall@me.com

(C2014 The Japanese Society of Veterinary Science

This is an open-access article distributed under the terms of the Creative Commons Attribution Non-Commercial No Derivatives (by-nc-nd) License $<$ http://creativecommons.org/licenses/by-nc-nd/3.0/>. tumor mutations [6]. We describe 2 novel $c$-KIT mutations in exon 11 (c.1663-1671del and c.1676T $>$ A) identified in 2 individual cases of canine mast cell tumors that responded favorably to imatinib mesylate.

Case 1 was an 11-year-old spayed female mongrel dog weighing $14.1 \mathrm{~kg}$ and referred to the Japan Small Animal Cancer Center with bilateral mandibular lymph node metastases from a mast cell tumor. The primary tumor on the muzzle had been completely resected by the referring veterinarian 1 month previously. Initial examination revealed bilateral enlarged mandibular lymph nodes measuring 2.2 $\times 1.8 \times 1.5 \mathrm{~cm}$ on the left and approximately $1 \mathrm{~cm}$ on the right. No relapse was detected on the muzzle. Cytological examination of the enlarged mandibular lymph nodes by aspiration biopsy showed metastatic tumor cells. Although chemotherapy was initiated with concurrent administration of intravenous vinblastine (Exal; Nipponkayaku, Tokyo, Japan) at $2 \mathrm{mg} / \mathrm{m}^{2}$ weekly and oral prednisolone (Predonin; Shionogi, Osaka, Japan) at 10-15 mg/day, the lymph node lesions progressed rapidly.

Case 2 was a 10-year-old castrated male Yorkshire terrier weighing $4.7 \mathrm{~kg}$ and referred to the Japan Small Animal Cancer Center with a mast cell tumor metastasis in the right inguinal lymph node. The primary tumor on the scrotum had been completely resected by the referring veterinarian 6 months previously. Initial examination revealed enlarged inguinal lymph nodes measuring $3.0 \times 4.0 \mathrm{~cm}$ on the right with no scrotal relapse detectable. No abnormality was found on thoracic radiographs. Abdominal radiographs suggested an enlarged internal iliac lymph node, and abdominal ultrasonography revealed splenomegaly with decreased uniformity of the splenic echo pattern and confirmed enlargement of 
both internal and external iliac lymph nodes. Cytological examination of the enlarged inguinal and internal iliac lymph nodes by aspiration biopsy showed metastatic tumor cells. Debulking surgery was subsequently performed, followed by intravenous vinblastine at $2 \mathrm{mg} / \mathrm{m}^{2}$ and oral prednisolone at $5 \mathrm{mg} /$ day. However, the inguinal lymph node metastases progressed rapidly. Despite a good clinical response to 70 $\mathrm{mg} / \mathrm{m}^{2}$ of lomustine (CeeNU; Bristol-Myers Squibb Co., NY, U.S.A.), this therapy had to be withdrawn due to elevated liver enzymes. Two months following the initial administration of lomustine, progression of lymph node lesions was detected again.

Imatinib mesylate (Imatib; Cipla Ltd., Mumbai, India, Glivec Tablets; Novartis Pharma KK, Tokyo, Japan) was administered orally each day after a meal at an initial dose of $10 \mathrm{mg} / \mathrm{kg}$. Prednisolone, diphenhydramine and famotidine were administered concomitantly. Although prednisolone had been administered in both cases for 2 months before imatinib treatment start, response to the tumors was not observed. Prednisolone was administered at the same dose (Case 1: $10 \mathrm{mg} /$ day, Case 2: $5 \mathrm{mg} /$ day) concurrently with imatinib in order to prevent Darier's sign and worsening general condition. In Case 1, masitinib (Masivet; AB Science, Paris, France) was administered orally at $13.3 \mathrm{mg} / \mathrm{m}^{2}$ after imatinib mesylate proved ineffective.

Genomic DNA was prepared from tumor cells collected by fine-needle aspiration using DNAzol Direct (Molecular Research Center Inc., Cincinnati, OH, U.S.A.). To determine the entire nucleotide sequence of exons, all primers used in the study were designed to be complementary to the intronic regions flanking the exon. The primers for canine $c-K I T$ exon 8, 9 and 11 are as follows: for exon 8, E8F: $5^{\prime}$-agccttggtgaggtgttcca-3', E8R: 5'-ctaccetgctgtccttccct-3'; for exon 9, E9F: 5'-atgccaattccaatgtgattgattg-3', E9R: 5'-attgatatggcaggcagagc-3'; and for exon 11: E11F: 5'-catttgttctctaccctaagtgcta-3', E11R: 5'-gttccctaaagtcattgttacacg-3'. Polymerase chain reaction (PCR) was performed in a total volume of $20 \mu l$, containing $1 \times$ PCR buffer, $2.5 \mathrm{mM}$ deoxynucleotide triphosphate, $4 \mu \mathrm{M}$ each forward and reverse primer and 0.1 unit of Taq polymerase (TaKaRa Taq ${ }^{\mathrm{TM}}$ Hot Start Version; Takara Bio Inc., Otsu, Japan). After an initial denaturation at $95^{\circ} \mathrm{C}$ for $120 \mathrm{sec}, 35$ cycles of amplification were carried out at $94^{\circ} \mathrm{C}$ for $30 \mathrm{sec}$, followed by annealing at $60^{\circ} \mathrm{C}$ for $30 \mathrm{sec}$ and extension at $72^{\circ} \mathrm{C}$ for $30 \mathrm{sec}$. The PCR products were separated by electrophoresis on a $4 \%$ agarose gel and visualized with EZVision (Amresco Inc., Solon, OH, U.S.A.). The expected sizes of the PCR products amplified from the wild-type $c$-KIT for exons 8,9 and 11 were $228 \mathrm{bp}$, $330 \mathrm{bp}$ and $277 \mathrm{bp}$, respectively. The nucleotide sequence of PCR products was determined by direct sequencing using an automated DNA sequencer (ABI 3730xI Analyzer; Applied Biosystems, Carlsbad, CA, U.S.A.). To ensure fidelity of the direct sequencing results, 3 PCR products prepared separately were sequenced based on the forward and reverse primers used for PCR.

Clinical response to imatinib mesylate in both cases was evaluated based on the RECIST guidelines [10]. The following criteria for antitumor effect were used: complete remission $(\mathrm{CR})=$ disappearance of all target lesions; partial remission $(\mathrm{PR})=\mathrm{a}$ decrease of $>30 \%$ in the sums of the longest diameters of target lesions; progressive disease $(\mathrm{PD})=\mathrm{an}$ increase of $>20 \%$ in the sum of the longest diameters of target lesions or the appearance of new lesions; and stable disease $(\mathrm{SD})=<30 \%$ decrease or $<20 \%$ increase in the sums of the longest diameters of target lesions. The duration of response was defined as the interval between the observed $\mathrm{PR}$ or $\mathrm{CR}$ and a recurrence.

In Case 1, aberrant bands that may have been derived from the wild-type and mutant $c$-KIT were detected by PCR analysis of $c-K I T$ exon 11 (Fig. 1). However, for c-KIT exons 8 and 9 , a single band from the wild type was detected. Sequence analysis of the exon 11 amplicon derived from 3 independently amplified PCR products revealed a 9-bp deletion (c.1663-1671del), corresponding to the deletion of $\mathrm{Gln}^{555}$-Try ${ }^{556}$ - Lys ${ }^{557}$ (Fig. 2). No mutation was found on either exon 8 or exon 9 in this case. As the lesion failed to respond to vinblastine, imatinib mesylate was used, taking into consideration the $c$-KIT mutation detected on exon 11 . PR and CR were achieved at days 7 and 33 following administration of imatinib mesylate, respectively. Despite ongoing administration of imatinib mesylate, a relapse of the mast cell tumor was observed in the left mandibular lymph nodes on day 73. The dosage of imatinib mesylate was therefore increased to $12.7 \mathrm{mg} / \mathrm{kg}$ and continued for 21 days, but the lesion showed no response to treatment. In this case, the remission duration was 66 days. After imatinib mesylate proved ineffective, masitinib was administered orally for 24 days; again, no response was observed. A transient response to $70 \mathrm{mg} / \mathrm{m}^{2}$ of lomustine lasted for 3 months; subsequently, the lesion continued to grow. The dog succumbed to the progression of mast cell tumor on day 233 after the first administration of imatinib mesylate.

In Case 2, a single band corresponding to the size of the wild type was detected by PCR analysis for $c$-KIT exons 8 , 9 and 11 . The dog was treated with imatinib mesylate and achieved CR by day 14. However, a relapse of the mast cell tumor was observed in the inguinal skin on day 269 , and the dog died by progression of mast cell tumor on day 328 . The remission duration in this case was 255 days. Since the mast cell tumor responded to imatinib mesylate despite the absence of an ITD, the nucleotide sequences of the PCR products from exons 8, 9 and 11 were examined. The nucleotide sequence obtained from the amplicon of exon 11 revealed a point mutation (c.1676T $>$ A) corresponding to $\mathrm{p}$.Val559Asp (Fig. 3); no mutations were found in either exon 8 or exon 9. These results were confirmed in 3 independently amplified PCR products.

We identified 2 novel $c$-KIT mutations on exon 11 (c.1663-1671del and c.1676T $>$ A) in 2 individual cases of canine mast cell tumors and observed that mast cell tumors with those mutations responded to imatinib mesylate treatment. The 9-bp deletion mutation caused a loss of 3 amino acids, corresponding to p.Gln555_Lys557del and the point mutation resulted in the substitution of valine by aspartic acid (p.Val559Asp) in the juxtamembrane domain of KIT. Previous studies in regard to canine mast cell tumors or 


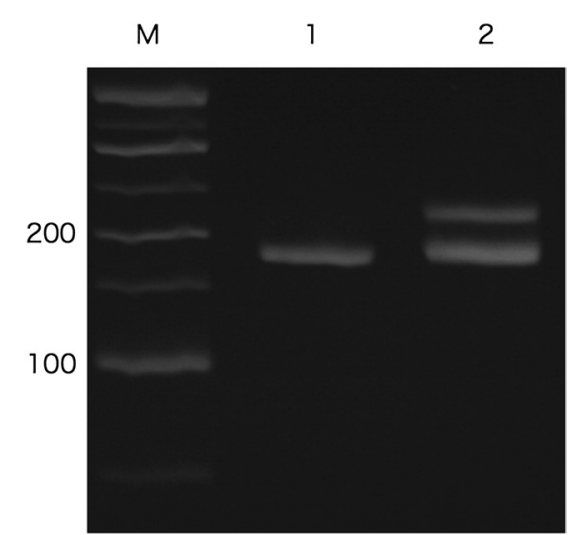

Fig. 1. Polymerase chain reaction amplification products of $c$-KIT exon 11 from Case 1. Lane M: 50-bp DNA ladder. Lane 1 shows a single band amplified from a normal dog genome, representing the wild-type $c-K I T$. Lane 2 shows aberrant bands amplified from Case 1. Although the difference of these bands looks like dozens of bases, a 9-bp deletion was subsequently identified in sequence analysis. The upper band may be a heteroduplex of the wild-type and mutant $c-K I T$.

gastrointestinal stromal tumors reported several deletion / insertion mutations (p.Glu555_Lys557delinsVal, p.Try556_ Lys557del, and p.Try556_Val558delinsPhe) in exon 11 [4, 6], and amino acids at 555-559 may be in hot spots for gain-of-function mutations [6]. It has been demonstrated that KIT carrying mutation (p.Glu555_Lys557delinsVal) caused constitutive ligand-independent phosphorylation which was dependently inhibited by a selective KIT inhibitor in vitro [6]. Indeed, the lesion of mast cell tumor carrying 9-bp deletion mutation in $c$-KIT exon 11 became small by treatment with imatinib mesylate in this study. Therefore, the 9-bp deletion mutation (p.Gln555_Lys557del) may cause constitutive phosphorylation and be a target for imatinib mesylate. On the other hand, p.Val559Asp which is the same mutation identified in Case 2 has been identified in human patients with gastrointestinal stromal tumor [9], who showed objective response to imatinib mesylate [7]. As mentioned above, Val559 may be in a hot spot of mutation. Then, mast cell tumor lesion in Case 2 responded to treatment with imatinib mesylate. Taken together, c. 1676T $>$ A (p. Val559Asp) may be related to mast cell tumor growth and be a possible target for imatinib mesylate.

There is no clear evidence that the 2 novel mutations presented in our study are gain-of-function mutations for canine mast cell tumors yet. An in vitro study may help clarify this hypothesis. Some cases without a $c-K I T$ mutation showed responsiveness to imatinib mesylate [3], while many cases with $c$-KIT mutations also showed a favorable response to imatinib mesylate $[3-5,11]$. Further research is necessary to better understand the association between each $c$-KIT mutation and tumor responsiveness to imatinib mesylate.

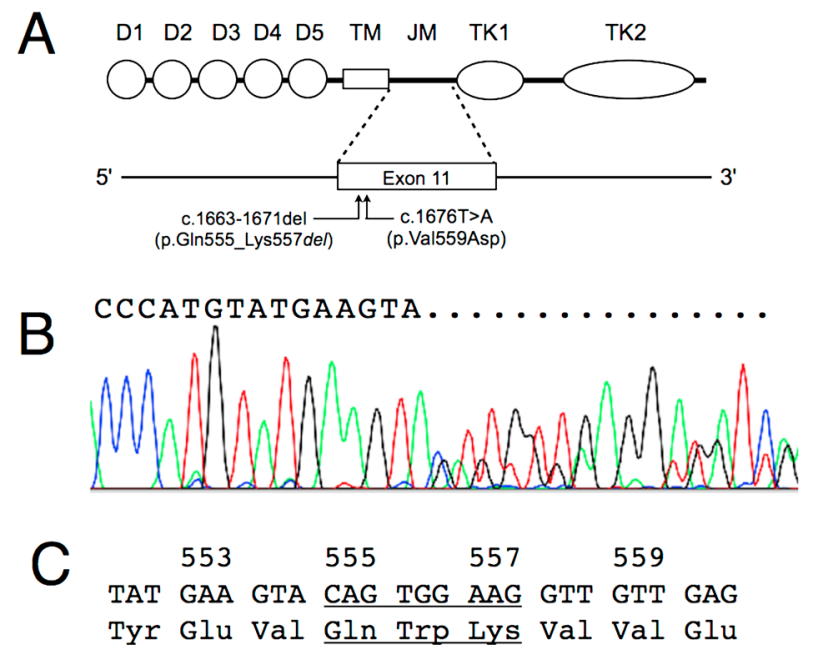

Fig. 2. A: Diagram of KIT domain structure and exon 11 indicating position of mutations in Case 1 and Case 2. Both are located in proximal region of exon 11. Detail mutation of p.Val559Asp is shown in Fig. 3. D1 to D5, immunoglobulin-like domains; TM, transmembrane domain; JM, juxtamembrane region; TK1, adenosine triphosphate binding domain; TK2, kinase activation loop. B: Sequence analysis of the exon 11 amplicon from Case 1. An overlapping curve is seen in the sequencing result, showing a 9-bp deletion mutation. $\mathrm{C}$ : The nucleotide and amino acid sequences of $c-K I T$ exon 11 from Case 1. The 9-bp deletion mutation, located 19 bases downstream of the first codon of exon 11, and the deleted amino acids are underlined.

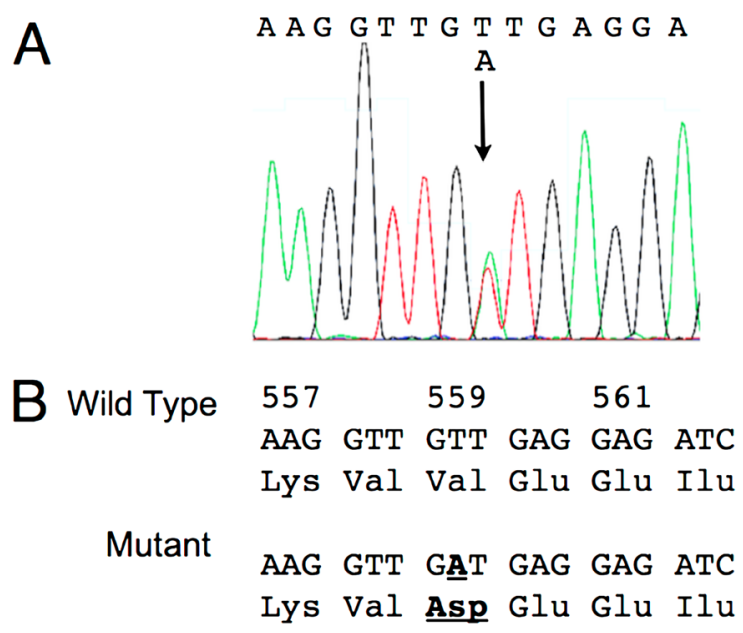

Fig. 3. A: Sequence analysis of the exon 11 amplicon from Case 2. The arrow indicates a point mutation (c.1676T $>$ A). $\mathrm{B}$ : Exon 11 nucleotide and amino acid sequences from Case 2. The point mutation (c.1676T $>$ A) and the corresponding amino acid substitution (p.Val559Asp) are underlined and shown by bold letters. 
ACKNOWLEDGMENTS. We are grateful to all staffs in the Japan Small Animal Medical Center for their assistant and dedicated nursing of the dogs. This research was supported by a Grant-in-Aid for Scientific Research (No. 23925032).

\section{REFERENCES}

1. Demetri, G. D., von Mehren, M., Blanke, C. D., Van den Abbeele, A. D., Eisenberg, B., Roberts, P. J., Heinrich, M. C., Tuveson, D. A., Singer, S., Janicek, M., Fletcher, J. A., Silverman, S. G., Silberman, S. L., Capdeville, R., Kiese, B., Peng, B., Dimitrijevic, S., Druker, B. J., Corless, C., Fletcher, C. D. and Joensuu, H. 2002. Efficacy and safety of imatinib mesylate in advanced gastrointestinal stromal tumors. N. Engl. J. Med. 347: 472-480. [Medline] [CrossRef]

2. Druker, B. J., Talpaz, M., Resta, D. J., Peng, B., Buchdunger, E., Ford, J. M., Lydon, N. B., Kantarjian, H., Capdeville, R., Ohno-Jones, S. and Sawyers, C. L. 2001. Efficacy and safety of a specific inhibitor of the BCR-ABL tyrosine kinase in chronic myeloid leukemia. N. Engl. J. Med. 344: 1031-1037. [Medline] [CrossRef]

3. Isotani, M., Ishida, N., Tominaga, M., Tamura, K., Yagihara, H., Ochi, S., Kato, R., Kobayashi, T., Fujita, M., Fujino, Y., Setoguchi, A., Ono, K., Washizu, T. and Bonkobara, M. 2008. Effect of tyrosine kinase inhibition by imatinib mesylate on mast cell tumors in dogs. J. Vet. Intern. Med. 22: 985-988. [Medline] [CrossRef]

4. Kobayashi, M., Kuroki, S., Ito, K., Yasuda, A., Sawada, H., Ono, K., Washizu, T. and Bonkobara, M. 2013. Imatinib-associated tumour response in a dog with a non-resectable gastrointestinal stromal tumour harbouring a $c$-kit exon 11 deletion mutation. Vet. J. 198: 271-274. [Medline] [CrossRef]

5. Kobayashi, M., Sugisaki, O., Ishii, N., Yamada, O., Ito, K., Kuroki, S., Sasaki, Y., Ono, K., Washizu, T. and Bonkobara, M. 2012. Canine intestinal mast cell tumor with c-kit exon 8 mutation responsive to imatinib therapy. Vet. J. 193: 264-267. [Medline] [CrossRef]

6. Letard, S., Yang, Y., Hanssens, K., Palmerini, F., Leventhal, P. S., Guery, S., Moussy, A., Kinet, J. P., Hermine, O. and Dubreuil, P. 2008. Gain-of-function mutations in the extracellular domain of KIT are common in canine mast cell tumors. Mol. Cancer Res. 6: 1137-1145. [Medline] [CrossRef]

7. Lim, K. H., Huang, M. J., Chen, L. T., Wang, T. W., Liu, C. L., Chang, C. S., Liu, M. C., Hsieh, R. K. and Tzen, C. Y. 2008. Molecular analysis of secondary kinase mutations in imatinibresistant gastrointestinal stromal tumors. Med. Oncol. 25: 207-213. [Medline] [CrossRef]

8. Ma, Y., Longley, B. J., Wang, X., Blount, J. L., Langley, K. and Caughey, G. H. 1999. Clustering of activating mutations in c-KIT's juxtamembrane coding region in canine mast cell neoplasms. J. Invest. Dermatol. 112: 165-170. [Medline] [CrossRef]

9. Tan, C. B., Zhi, W., Shahzad, G. and Mustacchia, P. 2012. Gastrointestinal stromal tumors: a review of case reports, diagnosis, treatment, and future directions. ISRN Gastroenterol. 2012: 595968. [Medline] [CrossRef]

10. Therasse, P., Arbuck, S. G., Eisenhauer, E. A., Wanders, J., Kaplan, R. S., Rubinstein, L., Verweij, J., Van Glabbeke, M., van Oosterom, A. T., Christian, M. C. and Gwyther, S. G. 2000. New guidelines to evaluate the response to treatment in solid tumors. European Organization for Research and Treatment of Cancer, National Cancer Institute of the United States, National Cancer Institute of Canada. J. Natl. Cancer Inst. 92: 205-216. [Medline] [CrossRef]

11. Yamada, O., Kobayashi, M., Sugisaki, O., Ishii, N., Ito, K., Kuroki, S., Sasaki, Y., Isotani, M., Ono, K., Washizu, T. and Bonkobara, M. 2011. Imatinib elicited a favorable response in a dog with a mast cell tumor carrying a c-kit c.1523A $>$ T mutation via suppression of constitutive KIT activation. Vet. Immunol. Immunopathol. 142: 101-106. [Medline] [CrossRef] 